\title{
Obesity as a risk factor for Alzheimer's disease: the role of adipocytokines
}

\author{
Liliana Letra • Isabel Santana • Raquel Seiça
}

Received: 21 July 2013 / Accepted: 3 February 2014 / Published online: 20 February 2014

(C) Springer Science+Business Media New York 2014

\begin{abstract}
Alzheimer's disease is the leading cause of dementia and the most prevalent neurodegenerative disease. It is an aging-related multi-factorial disorder and growing evidence support the contribution of metabolic factors to what was formerly thought to be a centrally mediated process. Obesity has already been recognized as an important player in the pathogenesis of this type of dementia, independently of insulin resistance or other vascular risk factors. Although the exact underlying mechanisms are still unknown, adipocyte dysfunction and concomitant alteration in adipocyte-derived protein secretion seem to be involved, since these adipocytokines can cross the blood-brain barrier and influence cognitive-related structures. Very few studies have assessed the role of adipocytokines dysfunction on cognitive impaired patients and yielded contradictory results. Interestingly, extensive research on the central effects of leptin in Alzheimer's diseasetransgenic mice has demonstrated its capacity to enhance synaptic plasticity and strength, as well as to prevent betaamyloid deposition and tau phosphorylation. In addition, adiponectin, the most abundant adipocytokine whose levels are inversely correlated to adiposity, has shown to be neuroprotective to hippocampal cells. Many other adipose-derived cytokines have mainly pro-inflammatory properties, being able to trigger and/or enhance central inflammatory cascades and also to influence the secretion of other adipocytokines involved in cognition. This paper pretends to review the
\end{abstract}

\section{Letra $\cdot$ I. Santana}

Serviço de Neurologia, Centro Hospitalar e Universitário de Coimbra, Portugal, Av. Bissaya Barreto - Praceta Prof Mota Pinto, 3000-075 Coimbra, Portugal

\section{Letra $(\bowtie) \cdot$ R. Seiça}

Instituto de Fisiologia da Faculdade de Medicina da Universidade de Coimbra, Pólo III- Ciências da Saúde Unidade Central, R/C Azinhaga de Santa Comba, Celas, 3000-548 Coimbra, Portugal e-mail: 1ilianaletra@gmail.com existing evidence on the contribution of adipocytokines dysfunction to the increased risk of dementia associated with midlife obesity, unraveling its insulin-independent effects on cognition.

Keywords Obesity · Adiposity · Adipocytokines · Dementia $\cdot$ Alzheimer's disease

\section{Introduction}

The identification of modifiable risk factors is crucial for the prevention of dementia, given the current limitations in its treatment. While aging is still the most important risk factor for late onset sporadic Alzheimer's Disease (AD), several studies have pointed high adiposity as an independent contributor for the development of this type of dementia (Gorospe and Dave 2007; Beydoun et al. 2008; Whitmer et al. 2008). In fact, life-long relation between adiposity and cognition has triggered some questions about the mechanisms by which adipose tissue might influence cerebral structures related to learning and memory, namely if its action is dependent on insulin resistance state (Fig. 1).

It is well-known that midlife obesity is a major risk factor for Type 2 Diabetes and these two disorders are frequently associated. Thereby, for many years, the impact of adiposity on $\mathrm{AD}$ incidence has been related to the effects of chronic hyperinsulinemia on the blood-brain-barrier and insulinreceptors activity that reduce insulin transport to the brain. This so called "brain insulin resistance state" might in turn increase $A \beta$ toxicity, tau hyperphosphorylation, oxidative stress and neuroinflammation, leading to neurodegeneration (Son et al. 2011; Luchsinger et al. 2004). It seems though that the influence of insulin metabolism on the clinical manifestation of $\mathrm{AD}$ is not constant over time. According to the Rotterdam Study, levels of insulin and insulin resistance were 


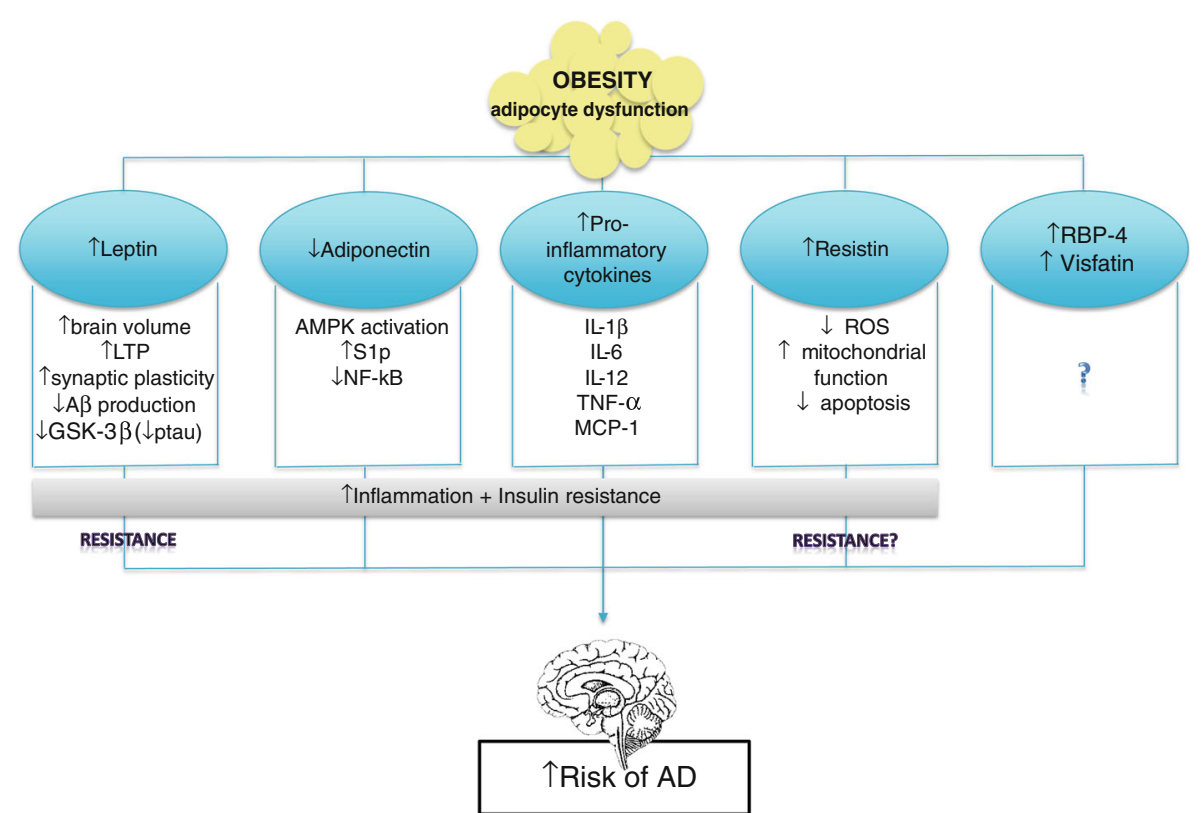

Fig. 1 Altered adipocytokine secretion in obesity and its pro-dementia effects. Dysfunctional adipose tissue presents an overproduction of proinflammatory adipocytokines (e.g. leptin, resistin) as well as reduced secretion of anti-inflammatory and insulin-sensitizing compounds (e.g. adiponectin). Despite peripheral hyperproduction of leptin in obese individuals, brain resistance develops. The same mechanism is proposed to resistin, though laking more consistent data. Unlike the former cytokines, adiponectin is inversely correlated to fat mass. Therefore its secretion

associated with a higher risk of $\mathrm{AD}$ only within 3 years of baseline (Schrijvers et al. 2010). Nevertheless, McNeilly et al. (2012) showed that cognitive deficits observed in dietinduced-obese animals were not prevented by insulin sensitizers, while Leboucher et al. (2013) have shown that obesity potentiate spatial learning deficits as well as hippocampal tau pathology in $\tau$-transgenic mice, independently of insulin resistance state. Both of these studies have highlighted the relevance of insulin-independent mechanisms in the increased risk of dementia related to obesity. Adipose tissue is a highly dynamic and metabolically active structure whose role has been underestimated for several decades. It is the primary storage site for excess energy, displaying characteristics of an endocrine organ that secretes a number of adipocytespecific factors known as adipocytokines. These molecules have metabolic, endocrine and inflammatory functions being able to cross the blood-brain barrier and, therefore, carry out its action on the brain (Kershaw and Flier 2004). In addition, disturbance of the blood-brain barrier is common in dementia, affecting central crossing of these adipose-derived compounds (Gustafson 2006). Much of the research in this area has focused leptin, the first adipocyte-derived signaling molecule discovered, and more recently other adipocytokines, showing evidence that these proteins might be actively implicated in cognition. Therefore, we present a review of the existing data on the contribution of obesity-related adipocytokine dysfunction to the increased risk of late onset $\mathrm{AD}$. diminish when adipocytes become dysfunctional, compromising its neuroprotective effects. $L T P$ long term potentiation, $A \beta$ amyloid-beta, GSK-3b glycogen synthase kinase beta, $A M P K$ adenosine monophosphateactivated protein kinase, $S 1 p$ sphingosin-1-phosphate, $N F-\kappa B$ nuclear factor kappa-light-chain-enhancer of activated B cells, $I L$ interleukin, $T N F$ - $a$ tumor necrosis factor alpha, $M C P-1$ monocyte chemoattractant protein-1, ROS reactive oxygen species, $R B P-4$ retinol-binding-protein 4

\section{Adiposity and adipocyte dysfunction}

Adiposity has been traditionally defined as an increase in total body mass, though visceral fat accumulation was found to better correlate with a cluster of metabolic abnormalities (Duvnjak and Duvnjak 2009). There are several adiposity markers, but Body Mass Index (BMI) has been the most widely used in clinical studies. Though BMI constitutes a strong indicator of total body fat tissue, this correlation decreases with age (Luchsinger 2008) and does not provide information on body composition neither distinguishes between visceral and subcutaneous fat (Cereda et al. 2007) while fat is redistributed throughout life, especially during and after middle age, from subcutaneous to intra-abdominal visceral deposits (Raguso et al. 2006).

Other measures of adiposity are waist circumference and waist-to-hip ratio, the first being more related to visceral fat deposits and with stronger correlation with adverse metabolic outcomes (Luchsinger 2008). Unfortunately, there are still no standardized plasmatic biomarkers that could correlate more directly with adipose tissue dysfunction.

In human obesity, adipose tissue alterations are far beyond adipocyte hypertrophy or hyperplasia and its redistribution. There are dynamic changes in its composition, mediated by macrophages that are locally recruited and polarized toward an inflammatory phenotype, associated with endothelial cell activation and fibrosis. In fact, dysfunctional adipose tissue 
presents an overproduction of pro-inflammatory adipocytokines (e.g. leptin) as well as a reduction of antiinflammatory and insulin-sensitizing compounds secretion (e.g. adiponectin) (Maury and Brichard 2010). Since adipokines are able to cross the blood-brain barrier, its deregulated production may not only promote well-known metabolic and cardiovascular detrimental outcomes, but also be implicated in the obesity-dementia association. Misiak et al. (2012) assumed that even subclinical inflammation of adipose tissue could play a role in central inflammation, triggering neurodegeneration cascades.

\section{Adipocytokines implicated in cognition}

Leptin

First described in 1994 (Zhang et al. 1994), leptin is the primary adipose hormone that conveys a saciety signal to the brain and its secretion is positively associated to the amount of adipocytes. There is evidence that support that leptin is not produced in the brain but actively transported across the blood-brain barrier by a saturable system (Kurrimbux et al. 2004; Banks et al. 1996). Its physiological action in the hypothalamus results in decreased body weight either by suppressing appetite and/or increasing energy expenditure. Leptin also plays an important role in the regulation of immune response, bone homeostasis, reproduction, and mood and emotion (Morris and Rui 2009). Besides this pleiotropic role, leptin has shown to promote beneficial effects on memory, including enhancement of long-term potentiation with consequent cognitive improvement when directly administered on dentate gyrus or CA1 hippocampal region (Shanley et al. 2001; Wayner et al. 2004) and also to influence hippocampal synaptic plasticity by enhancing N-methyl-D-aspartate (NMDA) receptors (Durakoglugil et al. 2005). Data from cell cultures and $\mathrm{AD}$ animal models show evidence of the role of this adipocytokine in amyloid precursor protein (APP) metabolism, namely a reduction of amyloid-beta $(\mathrm{A} \beta)$ peptide production by blocking $\beta$-secretase activity and increasing Apolipoprotein $\mathrm{E}$ (ApoE) dependent $\mathrm{A} \beta$ uptake (Fewlass et al. 2004). Moreover, leptin seems to promote phosphorylation (and deactivation) of glycogen synthase kinase beta (GSK-3 $\beta$ ), the main responsible for abnormal tau phosphorylation (Greco et al. 2009). Additionally, Li et al. (2012) demonstrated that obese leptin-resistant-mice $(\mathrm{db} / \mathrm{db})$ had multiple AD-like brain changes including increased phospho-tau and $\mathrm{A} \beta$ as well as decreased synaptic proteins, with consequent impairment of their performance in cognitive tasks. They also reported that metformin, a well-known antidiabetic agent, attenuates AD brain-like biochemical changes but not memory and spacial learning deficits. This suggests that other mechanisms, rather than insulin resistance sole, contribute to cognitive impairment in these obese mice. Despite extensive animal research on leptin, there are limited studies in human populations. A subgroup of the Framingham cohort and the Health ABC Study have demonstrated that higher leptin levels were associated with lower dementia risk and higher brain volume 7,7 or 4 years after leptin was assayed, respectively (Lieb et al. 2009; Holden et al. 2009). On the other hand, Rajagopalan et al. (2013) reported that elderly with higher leptin levels (obese) showed concomitant greater global brain atrophy, highlighting the deleterious effect of central leptin insufficiency associated with obesity. In fact, despite peripheral hyperproduction of leptin in obese individuals, brain resistance to its action will also develop. Bonda et al. (2014) demonstrated recently that besides up-regulation of leptin in AD patients' CSF and hippocampus, leptin receptor mRNA was decreased in the brain tissue and its protein was localized to neurofibrillary tangles. Interestingly, leptin CSF levels showed a positive relation with the Braak staging (plaque and tangle distribution at different stages of Alzheimer's disease progression) and were independent of age and BMI. It would be helpful to correlate these findings with adiponectin levels (in plasma and CSF) once the equation leptin/adiponectin is a more reliable marker of adipose tissue dysfunction and consequently of its metabolic effects (Satoh et al. 2004).

\section{Adiponectin}

Adiponectin (ACRP30) is the most abundant adipocytokine, presenting in plasma in globular, trimer, hexamer and highmolecular weight (HMW) isoforms (Fruebis et al. 2001; Takemura et al. 2007). Unlike leptin, adiponectin secretion is inversely correlated with fat mass and promotes antiinflammatory, antiangiogenic, antiatherogenic and vasodilatory action, exerting also beneficial effects on lipid and glucose profiles (Gustafson 2010). It is a peptide mainly produced by adipose tissue, without solid evidence of intracerebral production, and is able to act as a central regulator of energy homeostasis. The expression of two key receptors of adiponectin, AdipoR1 and AdipoR2, was observed in hippocampal neurons, and the neuroprotective role of adiponectin was proven, particularly in excitotoxic conditions (Jeon et al. 2009; Qiu et al. 2011). Neuroprotection is then mediated by adenosine monophosphate-activated protein kinase (AMPK) activation, which seems to minimize neural insult acting as a regulatory factor between neuronal growth and death in response to stress (Erol 2008), though recent data have highlighted the role of sphingolipid metabolism in the pleiotropic effects of adiponectin. In fact, activation of its receptors stimulates intracellular catabolism of ceramide, increasing the levels of its anti-apoptotic metabolite sphingosin-1-phosphate (S1p) (Holland et al. 2011; Turer and Scherer 2012). Additionally, Chan et al. (2012) raised the possibility that 
NF-KB (nuclear factor kappa-light-chain-enhancer of activated $B$ cells) suppression represents another mechanism underlying the effect of adiponectin against $A \beta$-induced neuronal cytotoxicity. A third receptor recently described, T-cadherin, remains with unclear brain expression and pathophysiologic significance, despite recognized importance in adiponectinmediated cardioprotection.

Involvement of adiponectin in $\mathrm{AD}$ or its prodromal stage (Mild Cognitive Impairment - MCI) has also been investigated in clinical studies, although in a limited number and with contradictory results. J-SHIPP Study (Shimanami Health Promoting Program - Kamogawa 2010) was the first crosssectional study to investigate abdominal fat distribution in individuals with MCI and was able to demonstrate the association between this prodromal stage and lower levels of plasma adiponectin (only in men), while Une et al. (2011) showed higher concentrations of plasma and cerebrospinal fluid (CSF) adiponectin in MCI compared with normal controls. According to the authors, this could play a role in the weight loss observed in the early stages of dementia. In our point of view, it could also translate a protective effort against a neurotoxic insult. More recently, Teixeira et al. (2013) demonstrated that circulating adiponectin levels were reduced in $\mathrm{MCI}$ and $\mathrm{AD}$ patients but did not predict progression to dementia. On other hand, Bigalke et al. (2011) and Warren et al. (2012) failed to demonstrate a correlation between plasmatic levels of this adipocytokine and AD. Nonetheless, correlation of these data with CSF adiponectin levels and dementia biomarkers, such as $\beta$-amyloid, tau and phosphotau, is still lacking and conflicting results from these few studies have not yet been elucidated. Future experiments should focus on the dynamics of adiponectin and its receptors on brain tissue, namely on hippocampus, once alterations in its structure and function are hallmarks of AD.

Interestingly, Pákáski et al. (2014) recently demonstrated that donepezil, an acetylcholinesterase inhibitor currently used in AD therapy, is able to regulate serum adipokines by reducing leptin and enhancing adiponectin. These findings are consistent to what was previously exposed, reinforcing the role of adipokines in the pathomechanism of AD.

\section{Visfatin and RBP-4}

Visfatin or Nicotinamide phosphoribosyltransferase (NAMPT) is a key enzyme in the synthesis of nicotinamide adenine dinucleotide (NAD), ubiquitously expressed and widely distributed in visceral adipose tissue and brain, including hippocampus and cerebral cortex. Its biological role is not entirely understood mas it seems to be insulin-sensitizer and a pro-inflammatory citokine (Al-Suhaimi and Shehzad 2013). Elevated serum levels of this protein have been associated with obesity and normal aging though brain levels are reduced, compromising NAD biosynthesis and promoting neurodegeneration (Adams 2008; Liu et al. 2012). A direct effect of this protein on the pathophysiology of AD remains unclear.

Retinol-binding-protein-4 (RBP-4), whose main function is to deliver vitamin A to tissues, was described by Yang and colleagues (2005) as an adipocytokine, though mainly secreted by hepatocytes. It seems to have a direct relation to BMI and a still controversial relation with insulin resistance (Rocha et al. 2013). Natural ageing is associated with a reduction in the retinoid levels in the central nervous system, which are dependent on the diet supply, transportation to the brain and the production/removal of end products (Goodman 2006). Retinoid receptors are preferentially located in structures involved in cognition (cerebral cortex, amygdala, hypothalamus, hippocampus and striatum), and there is evidence that they participate in synaptic plasticity as well as in learning and memory processing (Lane and Bailey 2005). Accordingly, several studies have already demonstrated that disruption of retinoid signaling pathways is directly implicated in the pathophysiology of Alzheimer's disease, namely in the amyloidogenic pathway (Misner et al. 2001; Husson et al. 2006; Corcoran et al. 2004). Whether obesity-related adipocyte dysfunction contributes to this central retinoid disruption remains unclear.

Resistin Resistin is an adipose tissue-specific hormone that antagonizes insulin action. Circulating resistin levels are decreased by anti-diabetic drugs such as rosiglitazone, and increased in diet-induced and genetic forms of obesity (Steppan et al. 2001). Recently, Lu et al. (2013) and Liu et al. (2013) demonstrated that this adipokine has neuroprotective effects. The first showed that resistin reduces 6-OHDA-induced apoptotic cell death in dopaminergic-like cells, which is accomplished by inhibiting oxidative stress and apoptosis. On the other hand, Liu et al. (2013) were the first to describe the protective effects of resistin against $A \beta$-induced neurotoxicity in AD. The mechanisms proposed include decrease levels of reactive oxygen species, improvement of mitochondrial function and prevention of apoptosis, though no changes were observed in the production of $A \beta$. However, the exact receptors that mediate these actions and whether there is a brain resistin-resistance state or more significant pro-inflammatory adverse effects in obese require further investigation.

\section{Other pro-inflammatory cytokines}

As previously discussed, there is a clear association between dysfunctional adipose tissue and low-grade inflammation due to increased secretion of numerous pro-inflammatory cytokines from hypertrophic adipocytes and recruited macrophages. Many of these cytokines are increased in obesity and may play an important role in several pathologies, including dementia, by promoting angiogenesis, inflammation, cell proliferation, and insulin resistance (Kim et al. 2011). 
Interleukin-6 (IL-6) is a protein that exerts an inhibitory action on adiponectin secretion (Kamogawa et al. 2010) and has peripheral and central adverse effects, being the hippocampus particularly vulnerable to its pro-inflammatory action. Tumor necrosis factor-alpha (TNF- $\alpha$ ) levels strongly correlate with BMI (Takemura et al. 2007) and have been implicated in the demential process, though inconsistently (Une et al. 2011). Guerreiro et al. (2007) showed that in MCI and AD patients there was a significant raise in the percentage of monocytes producing pro-inflammatory interleukins (IL-1 $\beta$, IL-6, IL-12) and $T N F-\alpha$ when compared with healthy controls. $M C P-1$ (monocyte chemoattractant protein-1, or CCL-2) has a key role in the recruitment of monocytes/macrophages into adipose tissue being also produced by neurons and glial cells, activating its receptor (CCR2) and contributing to pathological microgliosis and exacerbation of $A \beta$ pathology in animal models of AD. In humans with dementia, MCP-1 levels are increased in CSF and in the brain tissue (MCP-1 co-localizes with senile plaques); however, only MCP-1 levels in the CSF, and not in plasma, were associated with faster cognitive decline in patients with $\mathrm{MCI}$. This indicates that MCP-1-related inflammatory processes that are relevant for the disease progression are primarily localized in the brain, and probably not directly associated with peripheral tissue disorders (Westin et al. 2012). The relation between cognitive impairment and these inflammatory markers, which are not adipocyte-specific but are, instead, diffusely produced, is beyond the scope of this review.

\section{Conclusion}

In the past few years it has became increasingly clear that adipocyte dysfunction influences the risk and/or the rate of cognitive decline. Beyond its peripheral metabolic effects, several adipocytokines have been consistently implicated in this process, exerting differential protective or deleterious effects on cognitive-related structures. In our opinion, some of the conflicting results published to date may be explained, at least in part, by an "obesity paradox" in the assessment of the risk of dementia and its correlation to adiposity in different stages of life. Additionally, more accurate and standardized measures of adiposity are lacking.

Considering cognitive epidemiology, it seems reasonable to admit that Alzheimer Disease is a metabolic disorder, which incidence could be reduced with prevention policies. Therefore, efforts to understand metabolic signaling pathways associated with $\mathrm{AD}$, namely those involved in adipocyte-brain axis, should continue, while facing discouraging results in the search for specific treatment options.

Conflict of interest The authors declare that they have no conflicts of interest.

\section{References}

Adams JD Jr (2008) Alzheimer's disease, ceramide, visfatin and NAD. CNS Neurol Disord Drug Targets 7(6):492-498

Al-Suhaimi EA, Shehzad A (2013) Leptin, resistin and visfatin: the missing link between endocrine metabolic disorders and immunity. Eur J Med Res 18:12

Banks WA, Kastin AJ, Huang W, Jaspan JB, Maness LM (1996) Leptin enters the brain by a saturable system independent of insulin. Peptides 17(2):305-311

Beydoun MA, Beydoun HA, Wang Y (2008) Obesity and central obesity as risk factors for incident dementia and its subtypes: a systematic review and meta-analysis. Obes Rev 9(3):204-218

Bigalke B, Schreitmüller B, Sopova K, Paul A, Stransky E, Gawaz M, Stellos K, Laske C (2011) Adipocytokines and CD34 progenitor cells in Alzheimer's disease. PLoS One 6(5):e20286

Bonda DJ, Stone JG, Torres SL, Siedlak SL, Perry G, Kryscio R, Jicha G, Casadesus G, Smith MA, Zhu X, Lee HG (2014) Dysregulation of leptin signaling in Alzheimer disease: evidence for neuronal leptin resistance. J Neurochem 128(1):162-172

Cereda E, Sansone V, Meola G, Malavazos AE (2007) Increased visceral adipose tissue rather than BMI as a risk factor for dementia. Age Ageing 36(5):488-491

Chan KH, Lam KS, Cheng OY, Kwan JS, Ho PW, Cheng KK, Chung SK, Ho JW, Guo VY, Xu A (2012) Adiponectin is protective against oxidative stress induced cytotoxicity in amyloid-beta neurotoxicity. PLoS One 7(12):e52354

Corcoran JP, So PL, Maden M (2004) Disruption of the retinoid signalling pathway causes a deposition of amyloid beta in the adult rat brain. Eur J Neurosci 20(4):896-902

Durakoglugil M, Irving AJ, Harvey J (2005) Leptin induces a novel form of NMDA receptor-dependent long- term depression. J Neurochem 95(2):396-405

Duvnjak L, Duvnjak M (2009) The metabolic syndrome - an ongoing story. J Physiol Pharmacol 60(Suppl 7):19-24

Erol A (2008) An integrated and unifying hypotesis for the metabolic basis of sporadic Alzheimer's disease. JAD 13(3):241-253

Fewlass DC, Noboa K, Pi-Sunyer FX, Johnston JM, Yan SD, Tezapsidis N (2004) Obesity-related leptin regulates Alzheimer's Abeta. FASEB J 18(15): 1870-1878

Fruebis J, Tsao TS, Javorschi S, Ebbets-Reed D, Erickson MR, Yen FT, Bihain BE, Lodish HF (2001) Proteolytic cleavage product of 30$\mathrm{kDa}$ adipocyte complement-related protein increases fatty acid oxidation in muscle and causes weight loss in mice. Proc Natl Acad Sci U S A 98(4):2005-2010

Goodman AB (2006) Retinoid receptors, transporters, and metabolizers as therapeutic targets in late onset Alzheimer disease. J Cell Physiol 209(3):598-603

Gorospe EC, Dave JK (2007) The risk of dementia with increased body mass index. Age Ageing 36(1):23-29

Greco SJ, Sarkar S, Casadesus G, Zhu X, Smith MA, Ashford JW, Johnston JM, Tezapsidis N (2009) Leptin inhibits glycogen synthase kinase-3beta to prevent tau phosphorylation in neuronal cells. Neurosci Lett 455(3):191-194

Guerreiro RJ, Santana I, Brás JM, Santiago B, Paiva A, Oliveira C (2007) Peripheral inflammatory cytokines as biomarkers in Alzheimer's disease and mild cognitive impairment. Neurodegener Dis 4(6): 406-412

Gustafson D (2006) Adiposity indices and dementia. Lancet Neurol 5(8): 713-720

Gustafson DR (2010) Adiposity hormones and dementia. J Neurol Sci 299(1-2):30-34

Holden KF, Lindquist K, Tylavsky FA, Rosano C, Harris TB, Yaffe K (2009) Serum leptin level and cognition in the elderly: findings from the Health ABC study. Neurobiol Aging 30(9):1483-1489 
Holland WL, Miller RA, Wang ZV et al (2011) Receptor-mediated activation of ceramidase activity initiates the pleiotropic actions of adiponectin. Nat Med 17(1):55-63

Husson M, Enderlin V, Delacourte A, Ghenimi N, Alfos S, Pallet V, Higueret P (2006) Retinoic acid normalizes nuclear receptor mediated hypo-expression of proteins involved in beta-amyloid deposits in the cerebral cortex of vitamin A deprived rats. Neurobiol Dis 23(1):1-10

Jeon BT, Shin HJ, Kim JB et al (2009) Adiponectin protects hippocampal neurons against kainic acid-induced excitotoxicity. Brain Res Rev 61(2):81-88

Kamogawa K, Kohara K, Tabara Y, Uetani E, Nagai T, Yamamoto M, Igase M, Miki T (2010) Abdominal fat, adipose-derived hormones and mild cognitive impairment: the J-SHIPP Study. Dement Geriatr Cogn Disord 30(5):432-439

Kershaw EE, Flier JS (2004) Adipose tissue as an endocrine organ. J Clin Endocrinol Metab 89(6):2548-2556

Kim SM, Song J, Kim S, Han C, Park MH, Koh Y, Jo SA, Kim YY (2011) Identification of peripheral inflammatory markers between normal control and Alzheimer's disease. BMC Neurol 11:51

Kurrimbux D, Gaffen Z, Farrell CL, Martin D, Thomas SA (2004) The involvement of the blood-brain and the blood-cerebrospinal fluid barriers in the distribution of leptin into and out of the rat brain. Neuroscience 123(2):527-536

Lane MA, Bailey SJ (2005) Role of retinoid signalling in the adult brain. Prog Neurobiol 75(4):275-293

Leboucher A, Laurent C, Fernandez-Gomez FJ et al (2013) Detrimental effects of diet-induced obesity on $\tau$ pathology is independent of insulin resistance in $\tau$ transgenic mice. Diabetes 62(5):1681-1688

Li J, Deng J, Sheng W, Zuo Z (2012) Metformin attenuates Alzheimer's disease-like neuropathology in obese, leptin-resistant mice. Pharmacol Biochem Behav 101(4):564-574

Lieb W, Beiser AS, Vasan RS et al (2009) Association of plasma leptin levels with incident Alzheimer's disease and MRI measures of brain aging: the Framingham study. JAMA 302(23):2565-2572

Liu J, Chi N, Chen H, Zhang J, Bian Y, Cui G, Xiu C (2013) Resistin protection against endogenous $\mathrm{A} \beta$ neuronal cytotoxicity from mitochondrial pathway. Brain Res 1523:77-84

Liu LY, Wang F, Zhang XY, Huang P, Lu YB, Wei EQ, Zhang WP (2012) Nicotinamide phosphoribosyltransferase may be involved in agerelated brain diseases. PLoS One 7(10):e44933

Lu DY, Chen JH, Tan TW, Huang CY, Yeh WL, Hsu HC (2013) Resistin protects against 6-hydroxydopamine-induced cell death in dopaminergic-like MES23.5 cells. J Cell Physiol 228(3):563-571

Luchsinger JA, Tang MX, Shea S, Mayeux R (2004) Hyperinsulinemia and risk of Alzheimer disease. Neurology 63(7):1187-1192

Luchsinger JA (2008) Adiposity, hyperinsulinemia, diabetes and Alzheimer's disease. An epidemiological perspective. Eur J Pharmacol 585(1):119-129

Maury E, Brichard SM (2010) Adipokine dysregulation, adipose tissue inflammation and metabolic syndrome. Mol Cel Endocrinol 314(1): $1-16$

McNeilly AD, Williamson R, Balfour DJ, Stewart CA, Sutherland C (2012) A high-fat-diet-induced cognitive deficit in rats that is not prevented by improving insulin sensitivity with metformin. Diabetologia 55(11):3061-3070

Misiak B, Leszek J, Kiejna A (2012) Metabolic syndrome, mild cognitive impairment and Alzheimer's disease - The emerging role of systemic low-grade inflammation and adiposity. Brain Res Bull 89(3-4):144-149

Misner DL, Jacobs S, Shimizu Y, de Urquiza AM, Solomin L, Perlmann T, De Luca LM, Stevens CF, Evans RM (2001) Vitamin A deprivation results in reversible loss of hippocampal long-term synaptic plasticity. Proc Natl Acad Sci U S A 98(20):11714-11719

Morris DL, Rui L (2009) Recent advances in understanding leptin signaling and leptin resistance. Am J Physiol Endocrinol Metab 297(6): E1247-E1259
Pákáski M, Fehér A, Juhász A, Drótos G, Fazekas OC, Kovács J, Janka Z, Kálmán J (2014) Serum adipokine levels modified by donepezil treatment in Alzheimer's disease. J Alzheimers Dis 38(2):371-377

Qiu G, Wan R, Hu J, Mattson MP et al (2011) Adiponectin protects rat hippocampal neurons against excitotoxicity. Age 33(2):155-165

Raguso CA, Kyle U, Kossovsky MP, Roynette C, Paoloni-Giacobino A, Hans D, Genton L, Pichard C (2006) A 3-year longitudinal study on body composition changes in the elderly: role of physical exercise. Clin Nutr 25(4):573-580

Rajagopalan P, Toga AW, Jack CR, Weiner MW, Thompson PM (2013) Fat-mass-related hormone, plasma leptin, predicts brain volumes in the elderly. Neuroreport 24(2): 58-62

Rocha M, Bañuls C, Bellod L, Rovira-Llopis S, Morillas C, Solá E, Vítor VM, Hernández-Mijares A (2013) Association of serum retinol binding protein 4 with atherogenic dyslipidemia in morbid obese patients. PLoS ONE 8(11):e78670

Satoh N, Naruse M, Usui T, Tagami T, Suganami T, Yamada K, Kuzuya H, Shimatsu A, Ogawa Y (2004) Leptin-to-adiponectin ratio as a potential atherogenic index in obese type 2 diabetic patients. Diabetes Care 27:2488

Schrijvers EM, Witteman JC, Sijbrands EJ, Hofman A, Koudstaal PJ, Breteler MM (2010) Insulin metabolism and the risk of Alzheimer disease: the Rotterdam Study. Neurology 75(22):1982-1987

Shanley LJ, Irving AJ, Harvey J (2001) Leptin enhances NMDA receptor function and modulates hippocampal synaptic plasticity. J Neurosci 21(24):RC186

Son SM, Shin HJ, Mook-Jung I (2011) Insulin Resistance and Alzheimer's Disease. In: Zimering MB (ed) Topics in the prevention, treatment and complications of Type 2 Diabetes, 1 st edn. Intech pp 53-64

Steppan CM, Bailey ST, Bhat S, Brown EJ, Banerjee RR, Wright CM, Patel HR, Ahima RS, Lazar MA (2001) The hormone resistin links obesity to diabetes. Nature 409(6818):307-312

Takemura Y, Ouchi N, Shibata R, Aprahamian T, Kirber MT, Summer RS, Kihara S, Walsh K (2007) Adiponectin modulates inflammatory reactions via calreticulin receptor-dependent clearance of early apoptotic bodies. J Clin Invest 117(2):375-386

Turer AT, Scherer PE (2012) Adiponectin: mechanistic insights and clinical implications. Diabetologia 55(9):2319-2326

Teixeira AL, Diniz BS, Campos AC, Miranda AS, Rocha NP, Talib LL, Gattaz WF, Forlenza OV (2013) Decreased levels of circulating adiponectin in mild cognitive impairment and Alzheimer's disease. Neuromol Med 15(1):115-121

Une K, Takei YA, Tomita N, Asamura T, Ohrui T, Furukawa K, Arai H (2011) Adiponectin in plasma and cerebrospinal fluid in MCI and Alzheimer's disease. Eur J Neurol 18(7):1006-1009

Warren MW, Hynan LS, Weiner MF (2012) Lipids and adipokines as risk factors for Alzheimer's disease. J Alzheimers Dis 29(1): $151-157$

Wayner MJ, Armstrong DL, Phelix CF, Oomura Y (2004) Orexin-A (Hypocretin-1) and leptin enhance LTP in the dentate gyrus of rats in vivo. Peptides 25(6):991-996

Westin K, Buchhave P, Nielsen H, Minthon L, Janciauskiene S, Hansson O (2012) CCL2 is associated with a faster rate of cognitive decline during early stages of Alzheimer's disease. PLoS One 7(1):e30525

Whitmer RA, Gustafson DR, Barrett-Connor E, Haan MN, Gunderson EP, Yaffe K (2008) Central obesity and increased risk of dementia more than three decades later. Neurology 71(14):1057-1064

Yang Q, Graham TE, Mody N, Preitner F, Peroni OD, Zabolotny JM, Kotani K, Quadro L, Kahn BB (2005) Serum retinol binding protein 4 contributes to insulin resistance in obesity and type 2 diabetes. Nature 436(7049):356-362

Zhang Y, Proenca R, Maffei M, Barone M, Leopold L, Friedman JM (1994) Positional cloning of the mouse obese gene and its human homologue. Nature 372(6505):425-432 